\title{
Occurrence of pin nematode (Paratylenchus bukowinensis Micoletzky, 1922) and lesion nematodes (Pratylenchus spp. Filipjev, 1936) in celery crops (Apium graveolens L.)
}

\author{
Występowanie szpilecznika baldasznika (Paratylenchus bukowinensis \\ Micoletzky, 1922) oraz korzeniaków (Pratylenchus spp. Filipjev, 1936) \\ w uprawach selera (Apium graveolens L.)
}

\author{
Aneta Chałańska*, Aleksandra Bogumił, Daniel Sas
}

\begin{abstract}
Summary
Evaluation of occurrence of Pratylenchus spp. and Paratylenchus bukowinensis in celery crops was conducted during the growing season 2013-2014. To nematological analyses contained 31 soil samples collected from 11 voivodeships. Pin nematodes were isolated from 26 samples, whereas lesion nematodes from 25 soil samples. The highest numbers of $P$. bukowinensis were recorded in the samples originated from Wielkopolska Voivodeship while abundances of Pratylenchus spp. were the highest in Łódz Voivodeship. The results of this study suggest that celery crops are at high risk of infestation of these nematodes.
\end{abstract}

Key words: celery; plant parasitic nematodes; potential threat

\section{Streszczenie}

W sezonie wegetacyjnym 2013-2014 przeprowadzono ocenę upraw selera w kierunku obecności nicieni Pratylenchus spp. oraz Paratylenchus bukowinensis. Do analizy nematologicznej pobranych zostało 31 prób gleby, pochodzących z 11 województw. Szpilecznik baldasznik stwierdzony został w 26, a korzeniaki w 25 próbach gleby. Najwyższe liczebności $P$. bukowinensis odnotowano w województwie wielkopolskim, a Pratylenchus spp. najliczniej występowały w województwie łódzkim. Uzyskane wyniki świadczą o zagrożeniu upraw selera ze strony tych szkodników.

Słowa kluczowe: seler; nicienie pasożyty roślin; potencjalne zagrożenie

Instytut Ogrodnictwa

Konstytucji 3 Maja 1/3, 96-100 Skierniewice

*corresponding author: aneta.chalanska@inhort.pl 


\section{Wstęp / Introduction}

Seler należy do upraw małoobszarowych i nie prowadzono na nim wielu badań z zakresu nematologii. Dotychczasowe publikacje donoszą o występowaniu w Kanadzie, Włoszech, Stanach Zjednoczonych i Polsce w uprawie selera nicieni - pasożytów roślin, takich jak: Pratylenchus penetrans (Townshend 1963; Townshend i Wolynetz 1991), Meloidogyne incognita (Vovlas i wsp. 2008), Meloidogyne hapla (Townshend 1962; Starr i Mai 1976) Paratylenchus hamatus (Lownsbery i wsp. 1952) oraz Paratylenchus bukowinensis (Brzeski 1975). W glebach Polski powszechnie występuje guzak północny (M. hapla) (Kornobis 2003), który powoduje duże straty gospodarcze w uprawach roślin (Brzeski 1996; Brzeski i wsp. 1999; Karnkowski i wsp. 2013), w tym także korzeniowych (Dolna 1984). Nicień ten jest łatwo rozpoznawany przez producentów oraz doradców. Gatunek jest pospolity, powoduje charakterystyczne objawy żerowania i nie wymaga dokładnego monitoringu. Negatywny wpływ na wzrost i plonowanie selera mają także inne nicienie glebowe, między innymi występujący w Polsce szpilecznik baldasznik (P. bukowinensis) (Brzeski 1978) oraz korzeniaki (Pratylenchus spp.) (Townshend 1991; Brzeski 1998). Objawy ich żerowania, w odróżnieniu od guzaka północnego nie są specyficzne dla rodzaju i często mylone $\mathrm{z}$ chorobami powodowanymi przez inne patogeny. Dotychczas nie oceniono, na ile powszechnie szkodniki te występują w uprawach selera i jakie jest ich rozmieszczenie na terenie Polski. Ponadto nie wiadomo, czy osiągają liczebność mogącą stanowić zagrożenie i tym samym mieć wpływ na wydajność tej uprawy. W uprawie selera nie ma możliwości zwalczania tych nicieni metodami chemicznymi, a zastosowanie metod agrotechnicznych jest utrudnione ze względu na polifagizm tych szkodników.

Celem badań była ocena występowania korzeniaków i szpilecznika baldasznika w uprawie selera w wybranych województwach na terenie Polski.

\section{Materiały i metody / Materials and methods}

Badania prowadzono w latach 2013-2014. Przy współpracy z Wojewódzkimi Inspektoratami Ochrony Roślin i Nasiennictwa w trakcie sezonu wegetacyjnego, od lipca do listopada, pobrano 31 prób gleby pochodzących z 11 województw (rys. 1). Próbę stanowił $1 \mathrm{~kg}$ gleby, $\mathrm{z}$ której po wymieszaniu do analiz pobierano $250 \mathrm{~g}$.

Nicienie ekstrahowano z gleby zmodyfikowaną metodą Baermana (Luc i wsp. 2005). Wyizolowane nicienie zabito gorącą wodą, a następnie utrwalono $\mathrm{w}$ mieszaninie TAF (Courtney i wsp. 1955). Przy wykorzystaniu mikroskopu stereoskopowego określono liczebność nicieni, a ich identyfikację przeprowadzono przy pomocy mikroskopu świetlnego.


Rys. 1. Położenie miejsc poboru prób. Objaśnienia do mapy: puste kółka - brak obecności szpilecznika i korzeniaków; kółka zaciemnione w górnej połowie - obecność szpilecznika; kółka zaciemnione w dolnej połowie - obecność korzeniaków; kółka czarne obecność szpilecznika i korzeniaków

Fig. 1. Location of sampling sites. Explanation of the map: transparent circles - the absence of Pin Nematode and Lesion Nematodes; circles shaded in the top half - the presence of the Pin Nematode; circles shaded in the bottom half - the presence of Lesion Nematodes; black circles - the presence Pin Nematode and Lesion Nematodes 
Wyliczono wskaźnik stałości występowania (C) wyrażony jako stosunek liczby prób glebowych, w których wystąpił określony gatunek (Na) do ogólnej liczby pobranych prób $(\mathrm{N})$ wyrażony procentowo. Typ stałości występowania został określony na podstawie skali Tischlera (Trojan 1981), zgodnie z którą 0-25\% oznacza gatunki przypadkowe, 26-50\% to gatunki akcesoryczne, $51-75 \%-$ gatunki stałe, natomiast $76-100 \%$ - gatunki absolutnie stałe.

\section{Wyniki i dyskusja / Results and discussion}

$\mathrm{Na}$ podstawie analiz nematologicznych obecność szpilecznika baldasznika stwierdzono w 26 przebadanych próbach gleby (tab. 1), a korzeniaków - w 25 próbach (tab. 2). Występowanie badanych gatunków nicieni odnotowano w 10 województwach, przy czym w 24 próbach stwierdzono oba gatunki jednocześnie (tab. 3). Najwięcej prób z liczebnością nicieni z rodzaju Pratylenchus powyżej 50 osobników/100 g gleby zebrano w województwie łódzkim (2 próby), przy czym największą liczebność stwierdzono $\mathrm{W}$ próbie pochodzącej $\mathrm{z}$ miejscowości Brzeziny (91 osobników/100 g gleby). P. bukowinensis występował najliczniej w próbach zebranych w woje- wództwie wielkopolskim (średnia liczebność wynosiła 4640 osobników/100 g gleby), przy czym największą populację (5725 osobników/100 g gleby) odnotowano w próbie gleby pobranej z miejscowości Droszew.

Wartości wskaźników stałości wyliczonych dla badanych nicieni były bardzo wysokie i wynosiły odpowiednio $81 \%$ w przypadku korzeniaków oraz $84 \%$ dla szpilecznika baldasznika. Na podstawie skali Tischlera zaklasyfikowano je jako gatunki absolutnie stałe dla uprawy selera.

W Polsce szkodliwość P. bukowinensis w doświadczeniach szklarniowych i polowych wykazał Brzeski (1975, 1978). Przy porażeniu selera przez szpilecznika baldasznika obserwował on wyrastanie na korzeniach pierwszego rzędu licznych oraz krótkich korzeni bocznych tworzących kępki, na których następnie uwidaczniały się nekrozy. Przy liczebności P. bukowinensis 800 osobników/100 ml gleby objawy te wiązały się jednocześnie z istotnym spadkiem masy roślin i wielkości plonu (Brzeski 1975). Ponadto liczebność szpilecznika poniżej 100 osobników stwierdzana wiosną, w trakcie sezonu wegetacyjnego od lipca do września drastycznie rosła, osiągając liczebność przy której obserwowane były uszkodzenia roślin (Brzeski 1978). Karłowacenie roślin oraz chlorozy liści selera obserwowane były także

Tabela 1. Występowanie nicieni Paratylenchus bukowinensis w glebie pochodzącej z uprawy selera

Table 1. Occurrence of the Paratylenchus bukowinensis in soil originating from celery crop

\begin{tabular}{|c|c|c|c|c|c|c|}
\hline $\begin{array}{l}\text { Lp. } \\
\text { No. }\end{array}$ & $\begin{array}{l}\text { Województwo } \\
\text { Voivodeship }\end{array}$ & $\begin{array}{c}\text { Liczba } \\
\text { prób } \\
\text { gleby } \\
\text { Number } \\
\text { of soil } \\
\text { samples }\end{array}$ & $\begin{array}{c}\text { Liczba prób } \\
\text { ze stwierdzoną } \\
\text { obecnością } \\
\text { szpilecznika } \\
\text { baldasznika } \\
\text { P. bukowinensis } \\
\text { Number of soil } \\
\text { samples with pin } \\
\text { nematode } \\
\text { P. bukowinensis }\end{array}$ & \begin{tabular}{|c} 
Liczba prób \\
z liczebnością \\
szpilecznika baldasznika \\
P. bukowinensis powyżej \\
1000 osobników \\
w 100 g gleby \\
Number of soil samples \\
with pin nematode \\
P. bukowinensis \\
above 1000 individuals \\
in $100 \mathrm{~g}$ of soil
\end{tabular} & $\begin{array}{c}\text { Średnia liczebność } \\
\text { szpilecznika } \\
\text { baldasznika } \\
\text { P. bukowinensis } \\
\text { w } 100 \mathrm{~g} \text { gleby } \\
\text { Average number } \\
\text { of pin nematode } \\
\text { P. bukowinensis } \\
\text { in } 100 \mathrm{~g} \text { of soil }\end{array}$ & $\begin{array}{c}\text { Maksymalna liczebność } \\
\text { szpilecznika baldasznika } \\
\text { P. bukowinensis } \\
\text { w } 100 \text { g gleby } \\
\text { Maximum number } \\
\text { of pin nematode } \\
\text { P. bukowinensis } \\
\text { in } 100 \mathrm{~g} \text { of soil }\end{array}$ \\
\hline 1 & dolnośląskie & 4 & 3 & 2 & 1042 & 2702 (Pątnówek) \\
\hline 2 & lubuskie & 1 & 1 & 0 & 666 & $\begin{array}{l}666 \\
\text { (Międzyrzecz) }\end{array}$ \\
\hline 3 & tódzkie & 8 & 6 & 2 & 694 & 3808 (Karnków) \\
\hline 4 & małopolskie & 3 & 3 & 0 & 7 & 8 (Siedliska) \\
\hline 5 & mazowieckie & 4 & 3 & 0 & 7 & 17 (Lipsko) \\
\hline 6 & podlaskie & 2 & 2 & 0 & 83 & 161 (Siemiatycze) \\
\hline 7 & pomorskie & 1 & 0 & 0 & 0 & 0 \\
\hline 8 & świętokrzyskie & 3 & 3 & 0 & 22 & 40 (Pińczów) \\
\hline 9 & $\begin{array}{l}\text { warmińsko- } \\
\text {-mazurskie }\end{array}$ & 1 & 1 & 0 & 64 & 64 (Działdowo) \\
\hline 10 & wielkopolskie & 3 & 3 & 3 & 4640 & 5725 (Droszew) \\
\hline 11 & $\begin{array}{l}\text { zachodnio- } \\
\text { pomorskie }\end{array}$ & 1 & 1 & 0 & 0 & 3 (Złocieniec) \\
\hline \multicolumn{2}{|c|}{ Łącznie - Total } & 31 & 26 & 7 & $\begin{array}{l}\text { średnia } \\
\text { average }\end{array}$ & $\begin{array}{l}\text { maksymalnie } \\
\text { maximum }\end{array}$ \\
\hline
\end{tabular}


Tabela 2. Występowanie nicieni Pratylenchus spp. w glebie pochodzącej z uprawy selera

Table 2. Occurrence of the Pratylenchus spp. in soil originating from celery crop

\begin{tabular}{|c|c|c|c|c|c|c|}
\hline $\begin{array}{l}\text { Lp. } \\
\text { No. }\end{array}$ & $\begin{array}{l}\text { Województwo } \\
\text { Voivodeship }\end{array}$ & $\begin{array}{l}\text { Liczba prób } \\
\text { gleby } \\
\text { Number } \\
\text { of soil } \\
\text { samples }\end{array}$ & $\begin{array}{c}\text { Liczba prób } \\
\text { ze stwierdzoną } \\
\text { obecnością } \\
\text { korzeniaków } \\
\text { Pratylenchus } \\
\text { spp. } \\
\text { Number of soil } \\
\text { samples } \\
\text { with lesion } \\
\text { nematodes } \\
\text { Pratylenchus } \\
\text { spp. }\end{array}$ & $\begin{array}{c}\text { Liczba prób } \\
\text { z liczebnością } \\
\text { korzeniaków } \\
\text { Pratylenchus spp. } \\
\text { powyżej } \\
50 \text { osobników } \\
\text { w } 100 \text { g gleby } \\
\text { Number of soil } \\
\text { samples with } \\
\text { lesion nematodes } \\
\text { Pratylenchus spp. } \\
\text { above } \\
50 \text { individuals } \\
\text { in } 100 \text { g of soil }\end{array}$ & $\begin{array}{l}\text { Średnia liczebność } \\
\text { korzeniaków } \\
\text { Pratylenchus spp. } \\
\text { w } 100 \text { g gleby } \\
\text { Average number of } \\
\text { lesion nematodes } \\
\text { Pratylenchus spp. } \\
\text { in } 100 \mathrm{~g} \text { of soil }\end{array}$ & $\begin{array}{c}\text { Maksymalna liczebność } \\
\text { korzeniaków } \\
\text { Pratylenchus spp. } 100 \text { g gleby } \\
\text { Maximum number of lesion } \\
\text { nematodes Pratylenchus spp. } \\
\text { in } 100 \text { g of soil }\end{array}$ \\
\hline 1 & dolnośląskie & 4 & 4 & 0 & 15 & 30 (Nawojów Śląski) \\
\hline 2 & lubuskie & 1 & 1 & 0 & 39 & 39 (Międzyrzecz) \\
\hline 3 & łódzkie & 8 & 6 & 2 & 27 & 91 (Brzeziny) \\
\hline 4 & małopolskie & 3 & 2 & 0 & 13 & 36 (Czuszów) \\
\hline 5 & mazowieckie & 4 & 3 & 0 & 4 & 11 (Osmolin) \\
\hline 6 & podlaskie & 2 & 2 & 0 & 4 & 6 (Siemiatycze) \\
\hline 7 & pomorskie & 1 & 0 & 0 & 0 & 0 \\
\hline 8 & świętokrzyskie & 3 & 3 & 0 & 9 & 13 (Pińczów) \\
\hline 9 & $\begin{array}{l}\text { warmińsko- } \\
\text {-mazurskie }\end{array}$ & 1 & 1 & 1 & 60 & 60 (Działdowo) \\
\hline 10 & wielkopolskie & 3 & 2 & 1 & 22 & 63 (Kalisz) \\
\hline 11 & $\begin{array}{l}\text { zachodnio- } \\
\text { pomorskie }\end{array}$ & 1 & 1 & 0 & 0 & 17 (Złocieniec) \\
\hline Łącz & nie - Total & 31 & 25 & 4 & $\begin{array}{ll}\begin{array}{l}\text { średnia } \\
\text { average }\end{array} & 17\end{array}$ & $\begin{array}{l}\text { maksymalnie } \\
\text { maximum }\end{array} 91$ \\
\hline
\end{tabular}

Tabela 3. Liczba prób, w których stwierdzono tylko korzeniaki Pratylenchus spp. lub tylko szpilecznika baldasznika Paratylenchus bukowinensis oraz prób, w których jednocześnie występowały Pratylenchus spp. i Paratylenchus bukowinensis

Table 3. Number of soil samples with both pin nematode Paratylenchus bukowinensis and lesion nematodes Pratylenchus spp. or only with lesion nematodes Pratylenchus spp. or only with pin nematode Paratylenchus bukowinensis

\begin{tabular}{|c|c|c|c|c|c|c|}
\hline $\begin{array}{l}\text { Lp. } \\
\text { No. }\end{array}$ & $\begin{array}{l}\text { Województwo } \\
\text { Voivodeship }\end{array}$ & $\begin{array}{l}\text { Liczba } \\
\text { prób } \\
\text { gleby } \\
\text { Number } \\
\text { of soil } \\
\text { samples }\end{array}$ & $\begin{array}{l}\text { Liczba prób, } \\
\text { w których obecne } \\
\text { były jedynie } \\
\text { korzeniaki } \\
\text { Pratylenchus spp. } \\
\text { Number of soil } \\
\text { samples only with } \\
\text { lesion nematodes } \\
\text { Pratylenchus spp. }\end{array}$ & $\begin{array}{c}\text { Liczba prób, w których } \\
\text { obecny był jedynie } \\
\text { szpilecznik baldasznik } \\
P . \text { bukowinensis } \\
\text { Number of soil samples } \\
\text { only with pin nematode } \\
\text { P. bukowinensis }\end{array}$ & $\begin{array}{c}\text { Liczba prób, gdzie } \\
\text { stwierdzono jednocześnie } \\
\text { Pratylenchus spp. } \\
\text { i P. bukowinensis } \\
\text { Number of soil samples } \\
\text { both with pin nematode } \\
\text { P. bukowinensis and lesion } \\
\text { nematodes Pratylenchus } \\
\text { spp. }\end{array}$ & $\begin{array}{c}\text { Liczba prób, } \\
\text { gdzie nie stwierdzono } \\
\text { Pratylenchus spp. } \\
\text { i P. bukowinensis } \\
\text { Number of soil } \\
\text { samples without } \\
\text { pin nematode } \\
\text { P. bukowinensis and } \\
\text { lesion nematodes } \\
\text { Pratylenchus spp. }\end{array}$ \\
\hline 1 & dolnośląskie & 4 & 1 & 0 & 3 & 0 \\
\hline 2 & lubuskie & 1 & 0 & 0 & 1 & 0 \\
\hline 3 & łódzkie & 8 & 0 & 0 & 6 & 2 \\
\hline 4 & małopolskie & 3 & 0 & 1 & 2 & 0 \\
\hline 5 & mazowieckie & 4 & 0 & 0 & 3 & 1 \\
\hline 6 & podlaskie & 2 & 0 & 0 & 2 & 0 \\
\hline 7 & pomorskie & 1 & 0 & 0 & 0 & 1 \\
\hline 8 & świętokrzyskie & 3 & 0 & 0 & 3 & 0 \\
\hline 9 & warmińsko-mazurskie & 1 & 0 & 0 & 1 & 0 \\
\hline 10 & wielkopolskie & 3 & 0 & 1 & 2 & 0 \\
\hline 11 & zachodniopomorskie & 1 & 0 & 0 & 1 & 0 \\
\hline \multicolumn{2}{|c|}{ Łącznie - Total } & 31 & 1 & 2 & 24 & 4 \\
\hline
\end{tabular}


$\mathrm{w}$ przypadku występowania $\mathrm{w}$ tej uprawie innych gatunków szpileczników. Lownsberry i wsp. (1952) oraz Townshend (1962) przy dużym nasileniu $P$. hamatus, wynoszącym odpowiednio około 2203 i 1454 osobników/100 g gleby, stwierdzali na korzeniach liczne nekrozy oraz brak korzeni bocznych, porównywane przez Townshend (1962) do ogona szczura. Podobne uszkodzenia obserwował na selerze Oostenbrink i Besemer (1953) w przypadku niezidentyfikowanego do gatunku nicienia $\mathrm{z}$ rodzaju Paratylenchus. W obecnych badaniach liczebność powyżej 1000 osobników/100 g gleby odnotowano w 7 na 31 prób gleby, co stanowi 23\% zebranego materiału. Wskazuje to na duże zagrożenie uprawy selera w Polsce przez tego szkodnika.

Szkodliwość korzeniaków w uprawie selera na przykładzie $P$. penetrans wykazał Townshend (1962). Obecność tego szkodnika obserwował on w ponad $70 \%$ gospodarstw w Kanadzie, objętych przez niego monitoringiem. Przy liczebności $P$. penetrans około 9 osobników/100 g gleby, na korzeniach widoczne były pomarańczowe przebarwienia oraz nekrozy, określane jako choroba „,rdzawych korzeni”. Objawy te zostały przez niego potwierdzone w późniejszych badaniach na siewkach selera (Townshend 1963), gdzie dodatkowo obserwował on karłowacenie roślin. Istotny spadek masy, zarówno części nadziemnej, jak i korzeni roślin selera inokulowanych $P$. penetrans stwierdzili także Starr i Mai (1976). W warunkach Polski szkodliwość nicieni z rodzaju Pratylenchus w uprawie selera nie była badana. Jedyne dane dotyczące negatywnego wpływu korzeniaków na wzrost i plonowanie roślin można znaleźć w publikacjach Szczygieł i Danek (1975), Szczygieł (1981, 1983), Szczygieł i Rebandel (1985). Szczygieł i Rebandel (1982) podali przybliżone progi szkodliwości $P$. penetrans w uprawie truskawki. Są one zróżnicowane w zależności od odmiany i typu gleby, jednakże około 50 osobników/100 g gleby stwarza zagrożenie dla każdej uprawy truskawki. W przeprowadzonych analizach nematologicznych liczebność korzeniaków powyżej tej wartości stwierdzono w 4 próbach (około 13\% wszystkich przebadanych prób). Mimo braku informacji na temat progu szkodliwości nicieni z rodzaju Pratylenchus dla selera, należałoby się spodziewać, że taka liczebność może stanowić realne zagrożenie dla tej uprawy. Uzyskane wyniki potwierdzają wcześniejsze doniesienia o zagrożeniu uprawy selera przez szpilecznika baldasznika oraz korzeniaki i wskazują na potrzebę prowadzenia badań dotyczących występowania oraz szkodliwości nicieni w tej uprawie. Konieczna jest kontynuacja monitoringu i rozszerzenie go na pozostałe, nieuwzględnione województwa. Identyfikacja gatunku szkodliwego nicienia, określenie wielkości jego populacji oraz ustalenie progu szkodliwości jest podstawą do ustalenia odpowiedniego programu ochrony selera.

\section{Wnioski / Conclusions}

1. Obecność korzeniaków i szpilecznika baldasznika w ponad $80 \%$ przebadanych prób oraz stwierdzanie dużych liczebności tych szkodników w glebie wskazuje na potrzebę monitorowania populacji tych nicieni.

2. Ze względu na brak danych dotyczących progów szkodliwości korzeniaków dla uprawy selera, konieczne jest przeprowadzenie dalszych badań dotyczących występowania tych nicieni w uprawie selera.

\section{Literatura / References}

Brzeski M.W. 1975. Szkodliwość węgorka selerkowca (Paratylenchus bukowinensis Micol.) dla selerów. Roczniki Nauk Rolniczych, Seria E, Ochrona Roślin 5 (1): 23-29.

Brzeski M.W. 1978. Seasonal dynamics of Paratylenchus bukowinensis and some other nematodes. Roczniki Nauk Rolniczych, Seria E, Ochrona Roślin 7 (1): 67-74.

Brzeski M.W. 1996. Guzaki w uprawach polowych. Ochrona Roślin 40 (10): 4-5.

Brzeski M.W. 1998. Nematodes of Tylenchina in Poland and temperate Europe. Muzeum i Instytut Zoologii PAN, Warszawa, 396 pp.

Brzeski M.W., Górska A., Łabanowski G. 1999. Korzeniaki i guzaki w rozsadach roślin warzywnych i sadzonkach roślin ozdobnych. Ochrona Roślin 43 (7), s. 11.

Courtney W.D., Polley D., Miller V.L. 1955. TAF, an improved fixative in nematode technique. Plant Disease Reporter 39: $570-571$.

Dolna J. 1984. Guzak północny - Meloidogyne hapla na chwastach w marchwi i jej przedplonach. Ochrona Roślin 28 (5): 13-14.

Karnkowski W., Dobosz R., Stadnicka M., Saldat M. 2013. Wystąpienie guzaka północnego Meloidogyne hapla Chitwood, 1949 (Nematoda: Meloidogynidae) w sadzeniakach na terytorium Polski. [Occurence of the northern root-knot nematode Meloidogyne hapla Chitwood, 1949 (Nematoda: Meloidogynidae) in seed potatoes on the territory of Poland]. Progress in Plant Protection/Postępy w Ochronie Roślin 53 (2): 371-375.

Kornobis S. 2003. Diversity of Meloidogyne hapla Chitwood, 1949 population in Poland. Russian Journal of Nematology 12 (1): 31-38.

Lownsberry B.F., Stoddard E.M., Lownsberry J.W. 1952. Paratylenchus hamatus pathogenic to celery. Phytopathology 42 (12): $651-653$.

Luc M., Sikora R.A., Bridge J. 2005. Plant Parasitic Nematodes in Subtropical and Tropical Agriculture. CABI Bioscience, Egham, UK, $871 \mathrm{pp}$.

Oostenbrink M., Besemer A.F.H. 1953. Parasitaire aaltjes al seen oorzaak van "wortelrot" in de snijbloemencultuur en hun bestrijding met grondontsmettingsmiddelen. Mededelingen van de Landbouwhogeschool en de Opzoekingsstations van de Staat te Gent 18 (2): $335-349$.

Starr J.I., Mai W.F. 1976. Effect of soil microflora on the interaction of tree plant-parasitic nematodes with celery. Phytopatology 66: $1224-1228$.

Szczygieł A. 1981. Trials on susceptibility of strawberry cultivars to the root lesion nematode, Pratylenchus penetrans. Friut Science Reports 8 (3): 121-125. 
Szczygieł A. 1983. On the tolerance limit of strawberry plants to root lesion nematode Pratylenchus penetrans (Cobb). Fruit Science Reports 10 (3): 135-143.

Szczygieł A., Danek J. 1975. Doświadczenia nad szkodliwością Pratylenchus penetrans (Cobb) dla generatywnych podkładek drzew owocowych. [Experiments on the harmfulness of (the nematode) Pratylenchus penetrans (Cobb) to generative rootstocks of fruit trees]. Prace Instytutu Sadownictwa, Seria A 9: 153-166.

Szczygieł A., Rebandel Z. 1982. Szkodliwość korzeniaka szkodliwego (Pratylenchus penetrans) dla truskawki w warunkach polowych w glebie lekkiej. Roczniki Nauk Rolniczych, Seria E, Ochrona Roślin 12 (1/2): 175-183.

Szczygieł A., Rebandel Z. 1985. Wpływ korzeniaka szkodliwego (Pratylenchus penetrans) na wzrost dwóch generatywnych podkładek, antonówki i czereśni ptasiej, w warunkach polowych. Roczniki Akademii Rolniczej w Poznaniu 136: 209-214.

Townshend J.L. 1962. The root-lesion nematode, Pratylenchus penetrans (Cobb, 1917) Filip. \& Stek. 1941, in celery. Canadian Journal of Plant Science 42 (2): 314-322.

Townshend J.L. 1963. The pathogenicity of Pratylenchus penetrans to celery. Canadian Journal of Plant Science 3: 70-76.

Townshend J.L. 1991. Morphological observations of Pratylenchus penetrans from celery and strawberry in southern Ontario. Journal of Nematology 23 (2): 205-209.

Townshend J.L., Wolynetz M.S. 1991. Penetration of celery and alfalfa roots by Pratylenchus penetrans as affected by temperature. Journal of Nematology 23 (2): 194-197.

Trojan P. 1981. Ekologia biocenoz. s. 285-389. W: „Ekologia ogólna” (W. Jarosławska, red.). Wyd. IV. PWN, Warszawa, 420 ss.

Vovlas N., Lucarelli G., Sasanelli N., Troccoli A., Papajova I., Palomares-Rius J.E., Castillo P. 2008. Pathogenicity and host-parasite relationships of the root-knot nematode Meloidogyne incognita on celery. Plant Pathology 57 (5): 981-987. 